\title{
AN ENDOCRANIAL CAST OF A PHYTOSAUR FROM THE UPPER TRIASSIC BEDS OF WESTERN TEXAS
}

\author{
E. C. CASE \\ Department of Geology, The University of Michigan
}

NINE FIGURES

The expedition of 1927 from the Museum of Geology of the University of Michigan recovered a very complete cranial region of a large Phytosaur, probably the genus Leptosuchus, from the upper Triassic beds of Howard County, Texas. This specimen, no. 8409 of the Museum of Geology, is undistorted and the matrix was readily removed, making it possible to trace all of the foramina and obtain a plastic cast of the endocranium and the bony labyrinth of the inner ear. The specimen lacks the anterior portion of the walls of the brain case, the extreme tip of the dorsum sellae, and the major portion of the parasphenoid process. These portions were restored in plasticine from other specimens in the collection before the cast was made. Figure 1, of the left side of the specimen, shows the various structures and outlets. Figures 4, 5, and 6 are photographs of the plaster castrecast from the plastic cast.

Seen from above, the cast shows the narrowness of the brain case and the relatively slight development of the cerebral region. The absence of any epiphysial structures is probably due to the loss of the anterior portion of the roof of the brain case. A figure of an endocranial cast of a closely related form, Belodon buceros Cope, made by Cope and reproduced by the author in volume 32 of 'The Journal of Comparative Neurology, shows well-developed epiphysial 

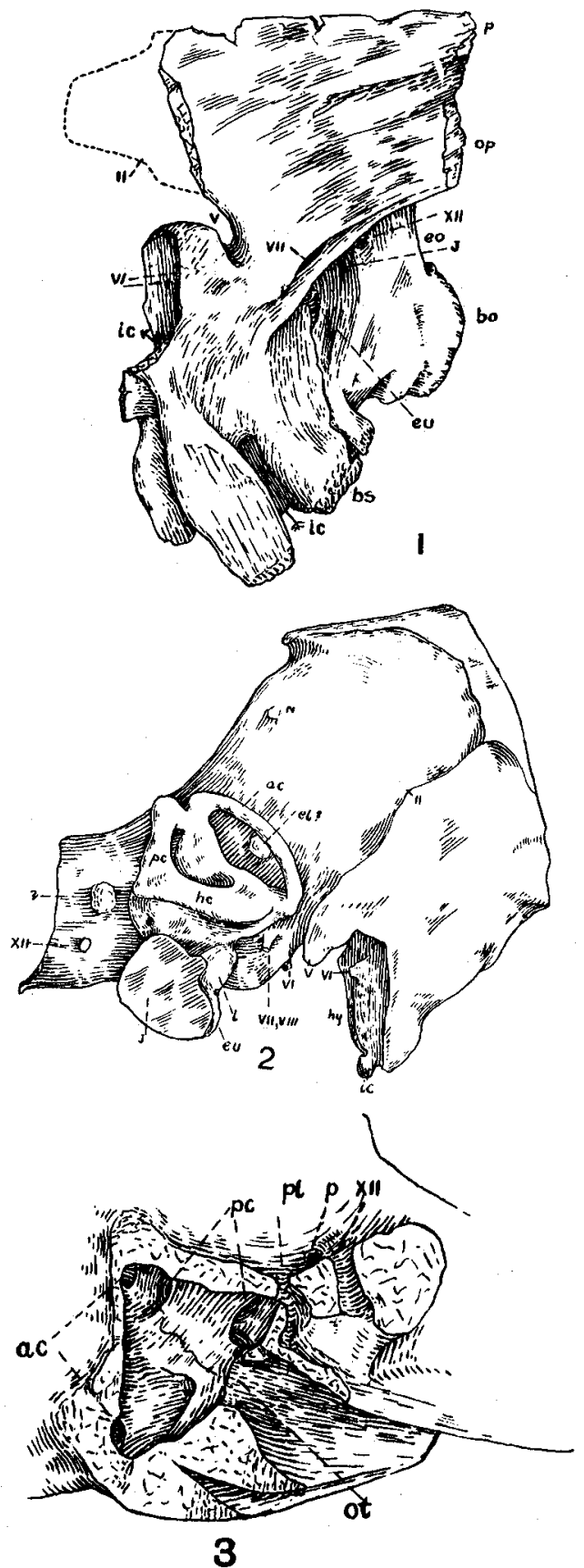

Figures 1 to 3 
structures. Such structures were undoubtedly present in all of the primitive reptiles even when, as in the Phytosaurs, there was no parietal foramen present. The region of the midbrain is the narrowest part of the cast, but is not otherwise marked off. It is well known that an endocranial cast of many of the reptiles does not give an exact replica of the brain, but a cast of the same region in other reptiles from the same locality and geological horizon (see figures of the endocranial cast from Desmatosuchus in The Journal of Comparative Neurology, vol. 32, p. 147) have the midbrain clearly marked. The cerebellar region and the anterior portion of the spinal cord are relatively large.

Seen from the side (fig. 2 and fig. 6) the cast shows the characteristic sharp curvature of the primitive reptilian brain. On either side of the cerebral region are two small prominences. The upper, near the top of the cast, marks the entrance of a foramen for a nutrient vessel. A fortunate break permitted this foramen to be followed until it broke up into minute ramifications within the substances of the bone. The lower prominence, just above the outlet for the Vth nerve, marks the opening of the single foramen that could not be cleaned out and followed. The opening is large, but quickly contracts until it could not be followed with the

Fig. 1 Left side of cranial region of specimen of Phytosaur from which cast was made. $\times \frac{1}{2}$. $b o$, basioccipital; $b s$, basisphenoid; eo, exoccipital; eu, pit at upper end of eustachian canal; $i c$, openings of the internal carotid canals; $j$, jugular-otic opening; $o p$, opisthotic; $p$, parietal; $I I, V$, etc., openings for eranial nerves.

Fig. 2 Right side of the endocranial cast with cast of the inner ear cavity in place. $\times 2$. ac, anterior vertical canal; $e u$, east of the pit at the top of the eustachian canal; el?, possible opening of the endolymphatic duct; $h c$, horizontal canal; $h y$, hypophysis; $i c$, internal carotid; $j$, cast of the jugular-otic opening; $l$, cast of the eavity for the lagena; $n$, opening of a nutrient foramen; ?, cast of a pit in the exoccipital above the foramen for the XIIth nerve; $I I, V$, etc., Iocation of the cranial nerves.

Fig. 3 View of the bony cavity of the ear from within. $\times 1 . a c$, anterior vertical canal; ot, jugular-otic opening; $p$, pit on the inner surface of the exoccipital; $p l$, perilymphatic foramen and duct, perhaps also groove for one or all of the IXth, Xth, and XIth nerves; $p c$, posterior vertical canal, the horizontal canal is seen just within the otie opening; XII, foramen for the XIIth nerve. 
finest needle. The opening is just above the middle of the anterior vertical semicircular canal and the course is apparently toward the canal. Osborn figured several such sharp depressions on the inner wall of the brain case of the dinosaur Tyrannosaurus and suggested that they may have been occupied by diverticula of the dura mater. In this specimen there are but two such depressions, symmetrically placed and apparently continuing in minute canals toward the cavity of the inner ear. The author is inclined to believe that they indicate the presence and position of the endolymphatic ducts, but this may be wrong, as the direction of the canal seems to lead anterior to the anterior vertical canal of the bony labyrinth.

Near the middle of the cast is the large prominence marking the position of the notch for the exit of the Vth nerve. The anterior wall of the brain case ended against cartilaginous or membranous extensions which completed the foramina for the $\mathrm{Vth}$ and IInd nerves. In making the cast the cavity was closed with plasticine, and the notches indicate the position of the exits of these nerves. Below the Vth nerve is the large cavity marking the position of the dorsum sellae, the posterior wall of the sella turcia. The anterior wall of the cavity is the impression of the anterior wall of the dorsum sellae, against which the posterior face of the hypophysis rested more or less closely. This surface is marked by several vertical ridges, the casts of grooves in the specimen, and by two small prominences near the center of the outer edges. The prominences mark the openings of two foramina which penetrate through the dorsum sellae; two similar prominences on the posterior face of the cavity mark the position of the other ends of the foramina, which from their position are evidently the outlets for the VIth nerves.

The general outline and the relatively large size of the hypophysis are indicated by the portion of the cast between the posterior wall of the sella and the parasphenoid process; the lower portion of this cavity was perforated by the foramina for the internal carotid arteries, indicated on the cast by small prominences. 


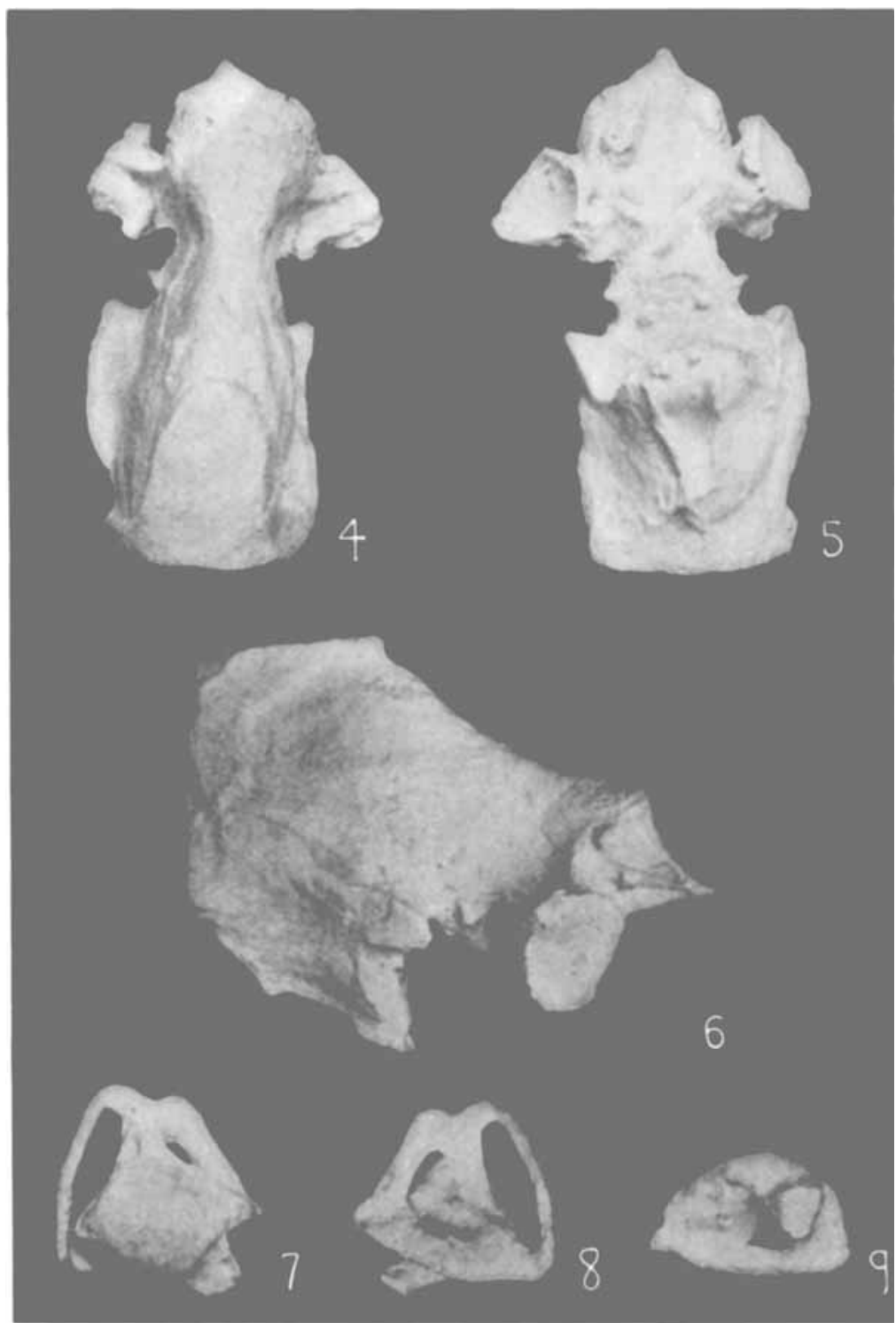

Fig. 4 Upper surface of endocranial east. $\times$ about $\frac{2}{3}$.

Fig. 5 Lower surface of same. $X$ about $\frac{2}{3}$.

Fig. 6 Left side of same, $\times$ about ?.

Fig. 7 Inner surface of cast of bony labyrinth; anterior vertical canal to left. $\times \frac{4}{3}$.

Fig. 8 Outer surface of same. $\times \frac{4}{5}$.

Fig. 9 Lower surface of same, showing cast of otic opening. $\times \frac{4}{5}$. 
Immediately behind the $V$ th nerve is a small prominence which marks the common foramen for the VIIth and VIIIth nerves. Unfortunately, the cast could not be made to represent the condition perfectly. The foramen perforates the inner wall of the brain cavity for a short distance and then divides, one branch going to the exterior, as shown in figure 1, and the other penetrating into the cavity of the inner ear near the junction of the anterior vertical and the horizontal canals.

Immediately posterior to the nerves just described there is a sharp angulation in the lower face of the cast marking the beginning of the hindbrain. In this specimen and in at least three others in the collection, the floor of the brain cavity is soft and without a good surface. It seems certain that the floor was, in part at least, cartilaginous. This rough and imperfect surface was covered with a thin layer of plasticine in making the cast, but as the details were checked from four specimens there can be, at most, but little error. It is probably because of the cartilaginous character of the floor of the brain case that no impression of the optic tracts is preserved.

Posterior to the angle in the base of the cast are the large prominences which mark the great common opening which included the jugular foramen, the otic opening, and the openings for the IXth, Xth, and XIth nerves. There are no traces of bony partitions in this opening, and the various passages must have been separated by cartilaginous or membranous walls. On the anterior face of the large projection are two smaller prominences. The upper is the cast of the cavity which sheltered the lagena; it joins the cast of the bony labyrinth just below the junction of the anterior vertical and the horizontal canals. The anterior wall of the cavity is clearly shown in the specimen, but the posterior wall must have been cartilaginous and has disappeared in the process of fossilization. The lagena was a simple sac with no trace of the slightest curvature. The lower prominence is the cast of a pit at the upper end of the suture be- 
tween the basioccipital and the basisphenoid bones and is in the proper position for the upper end of the eustachian canal. Just outside of the two prominences there is a low ridge which marks the position of a groove in the specimen. This groove is distinct from the cavity of the lagena and terminates in the eustachian pit below.

The remainder of the large projection is the cast of the otic-jugular opening. On its lower surface a ridge running forward and inward is the cast of a groove on the floor of the brain case of the specimen which probably marks the position of the jugular vein. On the upper surface there is a sharp ridge which is a cast of a groove best shown in figure 3 . This groove runs between the sharp ridge which marks the posterior edge of the stapedial groove in the specimen and the upper part of the exoccipital bone, and continues into the cranial cavity. As is shown in figure 3, a foramen enters this groove from the cavity of the inner ear at a point just opposite the junction of the posterior vertical and the horizontal canals. It is possible that this groove transmitted the IXth, $\mathrm{Xth}$, and XIth nerves and also, from the foramen, the perilymphatic duct into the brain cavity.

The posterior face of the large projection is the anterior face of the exoccipital bone. On both sides of the cavity behind the projection are small prominences which mark the ends of the canal for the XIIth nerve. Just above the inner end of this canal there is another small prominence, best seen on the left side of the cast, which is the filling of a small pit on the inner side of the exoccipital bone. This pit was cleaned out under a magnification of seven diameters and shown to have a complete bony bottom. Other than its association with the perilymphatic duct there is no indication of its meaning. Dr. C. J. Herrick has suggested to the author that it may possibly mark the position of one of the roots of the IXth nerve.

The cast of the cavity of the inner ear (figs. 7, 8, and 9) is as near perfect as could be hoped. The matrix was readily removed, leaving the surface of the bone clean and definite. 
The posterior vertical and horizontal canals and as much of the anterior vertical canal as could be reached were cleaned out on the right side. The anterior vertical canal of the left side was partially revealed by a break and was cleaned out. In making the cast it was necessary to plug the central part of the canals, in order to make it possible to remove the plastic cast. These vacancies were filled in the plaster cast. It is possible that the anterior vertical canal is at slightly too great an angle to the others, as it was difficult to retain the slender rods of plastic material in their exact position, but the divergence from the actual position can be only very slight. The inner wall of the cavity was evidently complete in life, but was broken in the specimen, as is shown in figure 3. The curvature and thickness of the walls made it very easy to restore them with a very satisfactory degree of accuracy. The exact size of the otic opening is conjectural, but cannot have been greatly different from the representation in the figures, as the continuation of the broken edges in plasticine outlined it nearly completely. The most striking thing about the cast is the small diameter of the anterior vertical canal as compared with the other two. This has been checked from both sides and is correct. It is to be remembered that the bony labyrinth must have been larger than the membranous inner ear and not necessarily of the same shape. It is possible that the larger bony labyrinth left room for the crossing of the membranous canals and for supporting structures, and it is possible that the smaller anterior vertical canal was more nearly filled by the membranous canal which it sheltered. For the same reason, the bony cavity shows no trace of the division of the sacculus from the utriculus. When the cast of the inner ear is placed in its proper position on the endocranial cast, the relatively large size is at once apparentsomewhat larger than in the modern alligator. 